\title{
Techniques of Proximal Root Reconstruction and Outcomes Following Repair of Acute Type A Aortic Dissection
}

\author{
Tyler M. Gunn, MD ${ }^{1}$, Sotiris C. Stamou, MD, PhD ${ }^{1 *}$, Nicholas T. Kouchoukos, MD², \\ Kevin W. Lobdell, MD³ ${ }^{3}$ Kamal Khabbaz, MD ${ }^{4}$, Lawrence H. Patzelt, MD, Robert C. Hagberg, MD \\ ${ }^{1}$ Department of Cardiothoracic Surgery, Baystate Medical Center, Springfield, Massachusetts, USA \\ 2 Division of Cardiothoracic Surgery, Missouri Baptist Medical Center, Saint Louis, Missouri, USA \\ ${ }^{3}$ Department of Thoracic and Cardiovascular Surgery, Sanger Heart and Vascular Institute, Carolinas Medical Center, Charlotte, \\ North Carolina, USA \\ ${ }^{4}$ Division of Cardiothoracic Surgery, Department of Surgery and The Cardiovascular Institute, Beth Israel Deaconess Medical Center, \\ Harvard Medical School, Boston, Massachusetts, USA \\ ${ }^{5}$ Thoracic and Cardiovascular Surgery, Spectrum Health, Fred and Lena Meijer Heart and Vascular Institute, Grand Rapids, Michigan, USA \\ ${ }^{6}$ Department of Cardiac Surgery, Hartford Hospital, Hartford, Connecticut, USA
}

\begin{abstract}
Background: The goal of this study was to compare the early and late outcomes of different techniques of proximal root reconstruction during the repair of acute Type $A$ aortic dissection, including aortic valve (AV) resuspension, aortic valve replacement (AVR), and a root replacement procedure.

Methods: All patients who underwent acute Type A aortic dissection repair between January 2000 and October 2010 at four academic institutions were compiled from each institution's Society of Thoracic Surgeons Database. This included 189 patients who underwent a concomitant aortic valve (AV) procedure; 111,21 , and 57 patients underwent AV resuspension, $A V R$, and the Bentall procedure, respectively. The median age of patients undergoing a root replacement procedure was significantly younger than the other two groups. Early clinical outcomes and 10-year actuarial survival rates were compared. Trends in outcomes and surgical techniques throughout the duration of the study were also analyzed.
\end{abstract}

Published by Science International Corp. ISSN 2325-4637

Fax +12037853552

E-Mail: aorta@scienceinternational.org

http://aorta.scienceinternational.org
Accessible online at:

http://aorta.scienceinternational.org
Results: The operative mortality rates were $17 \%, 29 \%$, and $18 \%$, for AV resuspension, AVR, and root replacement, respectively. Operative mortality $(p=0.459)$ was comparable between groups. Hemorrhage related re-exploration did not differ significantly between groups ( $p=0.182$ ); however, root replacement procedures tended to have decreased rates of bleeding when compared to AVR $(p=0.067)$. The 10-year actuarial survival rates for the AV resuspension, Bentall, and AVR groups were $72 \%, 56 \%$, and $36 \%$, respectively $(\log -\operatorname{rank} p=0.035)$.

Conclusions: The 10-year actuarial survival was significantly lower in those receiving AVR compared to those receiving root replacement procedures or AV resuspension. Operative mortality was comparable between the three groups.

Copyright $\odot 2016$ Science International Corp.

\section{Key Words}

Aorta - Aortic aneurysm - Aortic root • Aortic valve

* Corresponding Author:

Sotiris Stamou, MD, PhD

University of lowa Hospitals and Clinics

Cardiothoracic Surgery

759 Chestnut Street, Suite 4628, Springfield, MA 01199, USA

Tel.: +1 319467 5133; Fax: +1 413794 4212; E-Mail: cvsisfun@hotmail.com 


\section{Introduction}

Acute Type A aortic dissection is a rare and catastrophic condition with a high mortality rate [1-4]. The incidence is estimated to be between 2.9 and 4.7 per 100,000 persons per year $[5,6]$. The incidence of thoracic aortic dissection and the percentage of patients undergoing operative treatment may be increasing [7]. Emergent surgery is recommended after the diagnosis of Type A aortic dissection as the mortality rate increases considerably during the first 48 hours, approaching $60 \%$ with conservative treatment alone $[8,9]$. Midterm survival is higher in patients with thoracic aortic dissection who receive surgical intervention rather than medical treatment [6]. Medical therapy including volume management, anti-impulse and blood pressure control, and pain alleviation are frequently employed in patients with a history of stroke, comorbid conditions, and late presentation [10]. The aortic valve and root are frequently involved in the dissection, with as many as $40 \%$ of patients presenting with moderate or severe aortic regurgitation [11].

The three most common surgical techniques for proximal aortic root reconstruction during repair of acute Type A dissection include: aortic valve (AV) resuspension if the aortic valve and the sinuses are structurally normal, an aortic valve replacement (AVR) with a mechanical or tissue prosthesis if the valve is abnormal but the sinuses are normal, or a root replacement with a mechanical or tissue valve conduit if both the valve and sinuses are abnormal due to preexisting dilatation or extension of the intimal tear proximally to the level of the valve $[9,12]$. The objectives of our study were to evaluate the effect of the three proximal aortic root reconstruction techniques on early outcomes and late survival following acute Type A aortic dissection repair.

\section{Materials and Methods}

\section{Patients}

All patients who underwent aortic dissection repair between January 2000 and October 2010 at Beth Israel Deaconess Medical Center $(n=41)$, Carolinas Medical Center $(n=54)$, Missouri Baptist Medical Center $(n=21)$, and Meijer Heart and Vascular Institute $(n=73)$ were compiled from each institution's Society of Thoracic Surgeons (STS)
National Database. A total of 189 patients who underwent surgical repair for acute Type A aortic dissections with a concomitant AV procedure were included (111 patients who had an AV resuspension, 21 with an AVR, and 57 who underwent a root replacement). Patients who required only supracoronary graft placement without any intervention of the AV or aortic root were excluded $(n=62)$. Approval from the Institutional Review Boards of each center was obtained prior to this analysis. Consistent with the 1996 Health Insurance Portability and Accountability Act (HIPAA) regulations, patient confidentiality was maintained at all times.

CT angiography (CTA) or transesophageal echocardiography (TEE) was utilized to make the preoperative diagnosis of aortic dissection, which was later confirmed intraoperatively. Dedicated data-coordinating personnel prospectively generated a database containing demographic and procedural data, as well as preoperative outcomes. Late survival data was attained from the Social Security Death Index (http://www.genealogybank.com/gbnk/ssdi/). Follow-up was $97 \%$ complete.

\section{Definitions}

The definitions used in this study were attained from the STS National Database, which is available online at http:// www.sts.org/national-database. Acute Type A dissection was defined as any dissection of the ascending aorta with presentation within two weeks of symptoms. Diabetes was defined as a history of diabetes mellitus of any duration regardless of the need for antidiabetic medications. Cerebrovascular accident was defined as a history of central neurological deficit persisting for more than 24 hours. Chronic lung disease was defined as emphysema, chronic bronchitis, or pulmonary disease. Prolonged ventilation was defined as pulmonary insufficiency requiring ventilator support for more than 24 hours. Hemodynamic instability was defined as the presence of cardiac tamponade, shock, acute congestive heart failure, myocardial ischemia and/or infarction, or hypotension with a systolic blood pressure less than $80 \mathrm{~mm} \mathrm{Hg}$. Operative mortality includes all deaths occurring during the hospitalization in which the operation was performed and those deaths occurring after hospital discharge within 30 days of the procedure.

\section{Operative Technique}

TEE was used intraoperatively to confirm the diagnosis of Type A aortic dissection. Following a median sternotomy, cardiopulmonary bypass (CPB) was initiated with venous cannulation of the right atrium and arterial cannulation of the femoral or right axillary artery, based on surgeon's preference. To ensure myocardial protection, antegrade cold blood cardioplegia was administered via the ostia of the coronary arteries or retrograde through the coronary sinus. A vent was then placed in the left ventricle through the right superior pulmonary vein. Once a mean bladder temperature between 15 and $18^{\circ} \mathrm{C}$ was attained, the aortic clamp was removed, and the aortic arch was inspected. Distal aortic anastomosis was then performed, and antegrade aortic perfusion was initiated. The creation of distal anastomosis using an open distal anastomosis and hemiarch technique versus creation of the distal anastomosis with a clamp on was based on the 
surgeon's preference. If the aortic valve and sinuses were normal, resuspension of the aortic valve by placing three polypropylene pledgeted sutures at the three valve commisures was performed along with replacement of the ascending aorta with a straight tube graft. If the aortic valve was structurally abnormal but the sinuses were normal, AVR with mechanical or tissue prosthesis and supracoronary aortic grafting were employed. If the aortic valve and sinuses were abnormal from dilation (more than $5 \mathrm{~cm}$ ) or extension of the intimal tear to the valve, aortic root replacement (modified Bentall operation) with a tissue or mechanical valved conduit was used. Polytetrafluoroethylene strips were used to reinforce the proximal and distal anastomoses. In some patients, biological glue (BioGlue ${ }^{\circledR}$ surgical adhesive, Cryolife, Kennesaw, GA, USA) was used to better reapproximate the dissected layers.

\section{Data Analysis}

Univariate comparisons of preoperative, operative, and postoperative variables were preformed between groups of patients undergoing AV resuspension $(n=111)$, AVR $(n=21)$, and Bentall $(n=57)$ procedures. Continuous variables were tested using the analysis of variance (ANOVA) test for association, while categorical variables were assessed by the chisquare or Fisher exact test as appropriate according to the data distribution. Tukey posthoc analysis was performed for variables with statistically significant differences. KaplanMeier univariate unadjusted survival estimates were calculated and compared for all three aortic valve procedures using a log-rank test. A multivariable, stepwise, forward logistic regression analysis was conducted to determine independent predictors of operative mortality. The criterion for variable entry into the logistic model was a univariate probability level of $p<0.1$. The quality of fit of the logistic model was tested with the Hosmer-Lemeshow goodness-of-fit test. $p<0.05$ was considered significant. All analyses were performed using SPSS Statistics Version 21 (IBM Corp., Armonk, NY, USA).

\section{Results}

\section{Preoperative Characteristics}

Preoperative characteristics are summarized in Table 1. Tukey posthoc analysis indicated that patients undergoing root replacement procedures were significantly younger than those receiving an $\operatorname{AVR}(p=0.027)$, while the age difference between patients with root replacement procedures and those with valve resuspension was not statistically significant $(p=0.192)$.

\section{Operative Characteristics}

Operative patient characteristics of those receiving $A V$ resuspension, $A V R$, or root replacement procedures for acute Type $A$ aortic dissection repair are presented in Table 2. Median CPB time differed by valve procedure $(p<0.001)$ and was longest in root replacement procedures followed by AVR and AV resuspension (246, 203, and 163 min, respectively). Posthoc analysis indicated a significantly longer duration of CPB in root replacement procedures compared to AV resuspension $(p<0.001)$ or AVR $(p=0.027)$, while CPB duration was comparable between the $\mathrm{AV}$ resuspension and AVR groups ( $p=0.392)$. Arterial cannulation strategies varied between groups with increased axillary arterial cannulation in root replacement procedures and increased femoral access in AV resuspension $(p=0.006)$. BioGlue ${ }^{\circledR}$ was more frequently utilized in patients who underwent AVR compared to resuspension or the Bentall procedure $(p=0.026)$. Circulatory arrest time $(p=0.739)$ and retrograde $(p=0.598)$ and antegrade cerebral perfusion $(p=0.351)$ were not significantly different between the three groups. Patients who did not have antegrade or retrograde cerebral perfusion were repaired using profound hypothermic arrest only $(n=118)$. More patients who had AVR or root replacement underwent an open distal anastomotic technique compared to those who had resuspension $(p=0.028)$.

\section{Postoperative Characteristics}

Postoperative patient characteristics are displayed in Table 3. An increased incidence of cardiac arrest was observed in those patients receiving AVR compared to the other two groups $(p=0.029)$. Hemorrhage-related re-exploration did not differ significantly between groups $(p=0.182)$. Root replacement procedures had a lower rate of hemorrhage-related re-exploration compared to AVR; however, the differences were not statistically significant $(p=0.067)$. Operative mortality $(p=0.459)$ and hospital length of stay $(p=0.617)$ were comparable between groups. The operative mortality rates were $17 \%, 29 \%$, and $18 \%$,for AV resuspension, $A V R$, and root replacement, respectively.

\section{Multivariate Analysis}

In multivariable logistic regression analysis, hemodynamic instability (odds ratio $(O R)=1.9,95 \%$ confidence interval $(\mathrm{Cl})=0.03-0.75, p=0.021)$ and CPB time $>200$ min $(\mathrm{OR}=1.92,95 \% \mathrm{Cl}=0.04-0.54$, $p=0.004$ ) emerged as independent predictors of operative mortality. 
Table 1. Preoperative patient characteristics.

\begin{tabular}{|c|c|c|c|c|}
\hline Variable $^{a}$ & $\begin{array}{l}\text { Resuspension } \\
(n=111)\end{array}$ & $\begin{array}{l}\text { AVR } \\
(n=21)\end{array}$ & $\begin{array}{l}\text { Bentall } \\
(n=57)\end{array}$ & $p$ \\
\hline Age, years & $60(20-82)$ & $65(39-84)$ & $56(19-80)$ & 0.028 \\
\hline Female & $31(28 \%)$ & $6(29 \%)$ & $18(32 \%)$ & 0.884 \\
\hline Diabetes & $9(8 \%)$ & $0(0 \%)$ & $3(5 \%)$ & 0.347 \\
\hline Hypertension & 92 (83\%) & 17 (81\%) & $41(72 \%)$ & 0.247 \\
\hline $\mathrm{EF}$ & $55(27-73)$ & $55(15-65)$ & $55(35-65)$ & 0.118 \\
\hline COPD & $8(7 \%)$ & $4(21 \%)$ & $3(5 \%)$ & 0.099 \\
\hline Creatinine & $1.20(0.50-12.5)$ & $1.10(0.70-2.20)$ & $1.05(0.60-2.60)$ & 0.284 \\
\hline Hemodynamic instability & $17(17 \%)$ & $2(10 \%)$ & $4(7 \%)$ & 0.180 \\
\hline Arrhythmias & $11(10 \%)$ & $6(29 \%)$ & $7(12 \%)$ & 0.062 \\
\hline History of CVA & $9(8 \%)$ & $2(10 \%)$ & $4(7 \%)$ & 0.930 \\
\hline$E F<40$ & $6(11 \%)$ & $4(24 \%)$ & $1(3 \%)$ & 0.086 \\
\hline
\end{tabular}

Table 2. Operative patient characteristics.

\begin{tabular}{|c|c|c|c|c|}
\hline Variable $^{a}$ & $\begin{array}{l}\text { Resuspension } \\
(n=111)\end{array}$ & $\begin{array}{l}\text { AVR } \\
(n=21)\end{array}$ & $\begin{array}{l}\text { Bentall } \\
(n=57)\end{array}$ & $p$ \\
\hline CPB time $>200 \mathrm{~min}$ & $33(30 \%)$ & 10 (50\%) & $40(70 \%)$ & $<0.001$ \\
\hline CPB time, min & $163(31-391)$ & $203(100-267)$ & $246(100-684)$ & $<0.001$ \\
\hline Circulatory arrest time, min & $1.5(0-90)$ & $13.5(0-30)$ & $18(0-62)$ & 0.739 \\
\hline \multicolumn{5}{|l|}{ Distal anastomotic technique } \\
\hline Distal with cross-clamp & $43(39 \%)$ & $2(10 \%)$ & $17(30 \%)$ & 0.028 \\
\hline Open distal & $71(64 \%)$ & $19(90 \%)$ & $40(70 \%)$ & \\
\hline Hemiarch technique & $58(52 \%)$ & $14(67 \%)$ & $24(42 \%)$ & 0.140 \\
\hline Total arch replacement & $9(8 \%)$ & $1(5 \%)$ & $8(14 \%)$ & 0.340 \\
\hline Arterial cannulation & & & & 0.006 \\
\hline Axillary & $45(41 \%)$ & $6(29 \%)$ & $29(51 \%)$ & - \\
\hline Femoral & $66(59 \%)$ & $15(71 \%)$ & $28(49 \%)$ & - \\
\hline Retrograde cerebral perfusion & $12(11 \%)$ & $2(10 \%)$ & $9(16 \%)$ & 0.598 \\
\hline Antegrade cerebral perfusion & $24(22 \%)$ & $6(29 \%)$ & $18(32 \%)$ & 0.351 \\
\hline BioGlue ${ }^{\circledast} /$ felt strip & & & & 0.026 \\
\hline BioGlue $^{\oplus}$ & $56(56 \%)$ & $16(76 \%)$ & $24(54 \%)$ & - \\
\hline Felt strip & $26(26 \%)$ & $2(10 \%)$ & $11(20 \%)$ & - \\
\hline Both & $8(8 \%)$ & $0(0 \%)$ & $7(13 \%)$ & - \\
\hline
\end{tabular}

${ }^{a}$ Continuous data are shown as median (range) and categorical data are shown as $n(\%)$. $A V R=$ aortic valve replacement; $C P B=$ cardiopulmonary bypass. 


\section{Survival Analysis}

Unadjusted Kaplan-Meier survival estimates are shown in Figure 1. Patients undergoing AV resuspension, AVR, and the Bentall procedure, had median follow up time of 2,229 days (range 1-4802), 1,836 days (range 1-4,001), and 2,190 days (range 1-4,132), respectively ( $p=0.148)$. The actuarial 10-year survival rates for $\mathrm{AV}$ resuspension, root replacement, and AVR were $72 \%, 56 \%$, and $36 \%$, respectively (Figure 1, log-rank $p=0.035$ ), and the corresponding actuarial 5 -year survival rates were $75 \%, 68 \%$, and $60 \%$. The increased 10-year survival of patients undergoing AV resuspension compared to AVR was statistically significant ( $p=0.011)$, but the differences comparing the AVR and root replacement and AV resuspension groups were not $(p=0.171$ and $p=0.220$, respectively). There was an increase in the proportion of patients receiving AVR from 2000 to 2010 (Figure 2).

\section{Discussion}

Our study is among the first to compare postoperative outcomes and 10-year survival rates for patients undergoing AVR, AV resuspension, or root replacement procedures during acute Type $A$ aortic dissection repair. Notably, we observed a decreased 10-year survival rate in patients undergoing AVR.

\section{Preoperative Characteristics and Morbidity}

Patients receiving root replacement procedures were significantly younger than those undergoing AVR. We theorize that due to the more extensive dissection in younger patients causing significant root destruction, root replacement is more frequently required in this population. Patients who underwent AVR tended to be older and have increased incidences of chronic obstructive pulmonary disease, arrhythmias, and low ejection fraction; thus, their expected survival was lower compared to the resuspension and root replacement groups. More elderly patients likely had preexisting valve pathology and comorbidities prior to thoracic aortic dissection that may have influenced the higher rate of AVR and worse outcomes.

\section{Operative Mortality}

Surgical repair of Type A aortic dissection has traditionally carried a high rate of mortality. Our total operative mortality was $19 \%$, which can be further divided into $17 \%, 29 \%$, and $18 \%$ for $A V$ resuspension, AVR, and root replacement procedure, respectively. These differences in operative mortality were not statistically

Table 3. Postoperative patient characteristics.

\begin{tabular}{lllll}
\hline Variable & $\begin{array}{l}\text { Resuspension } \\
(\mathbf{n = 1 1 1 )}\end{array}$ & $\begin{array}{l}\text { AVR } \\
(\mathbf{n = 1 1 1 )}\end{array}$ & $\begin{array}{l}\text { Bentall } \\
(\mathbf{n = 5 7 )}\end{array}$ & $\mathbf{p}$ \\
\hline Deep sternal wound infection & $1(1 \%)$ & $0(0 \%)$ & $2(3.7 \%)$ & 0.361 \\
Prolonged ventilation & $52(49 \%)$ & $5(26 \%)$ & $12(22 \%)$ & 0.115 \\
Acute renal failure & $24(22 \%)$ & $4(21 \%)$ & $6(13 \%)$ & 0.991 \\
Hemodialysis & $9(9 \%)$ & $1(6 \%)$ & $8(16 \%)$ & 0.627 \\
Hemorrhage-related & $22(21 \%)$ & $7(37 \%)$ & $6(11 \%)$ & 0.029 \\
re-exploration & $7(7 \%)$ & $5(26 \%)$ & $9(17 \%)$ & 0.783 \\
Cardiac arrest & $22(21 \%)$ & $3(16 \%)$ & $12(22 \%)$ & 0.730 \\
Stroke & $30(28 \%)$ & $5(26 \%)$ & $10(0-99)$ & 0.617 \\
Atrial fibrillation & $12(0-70)$ & $12(0-45)$ & $10(18 \%)$ & 0.459 \\
Length of stay, days & $19(17 \%)$ & $6(29 \%)$ & \\
Operative mortality & & & \\
\hline
\end{tabular}

a Continuous data are shown as median (range) and categorical data are shown as $\boldsymbol{n}(\%)$.

AVR = aortic valve replacement. 


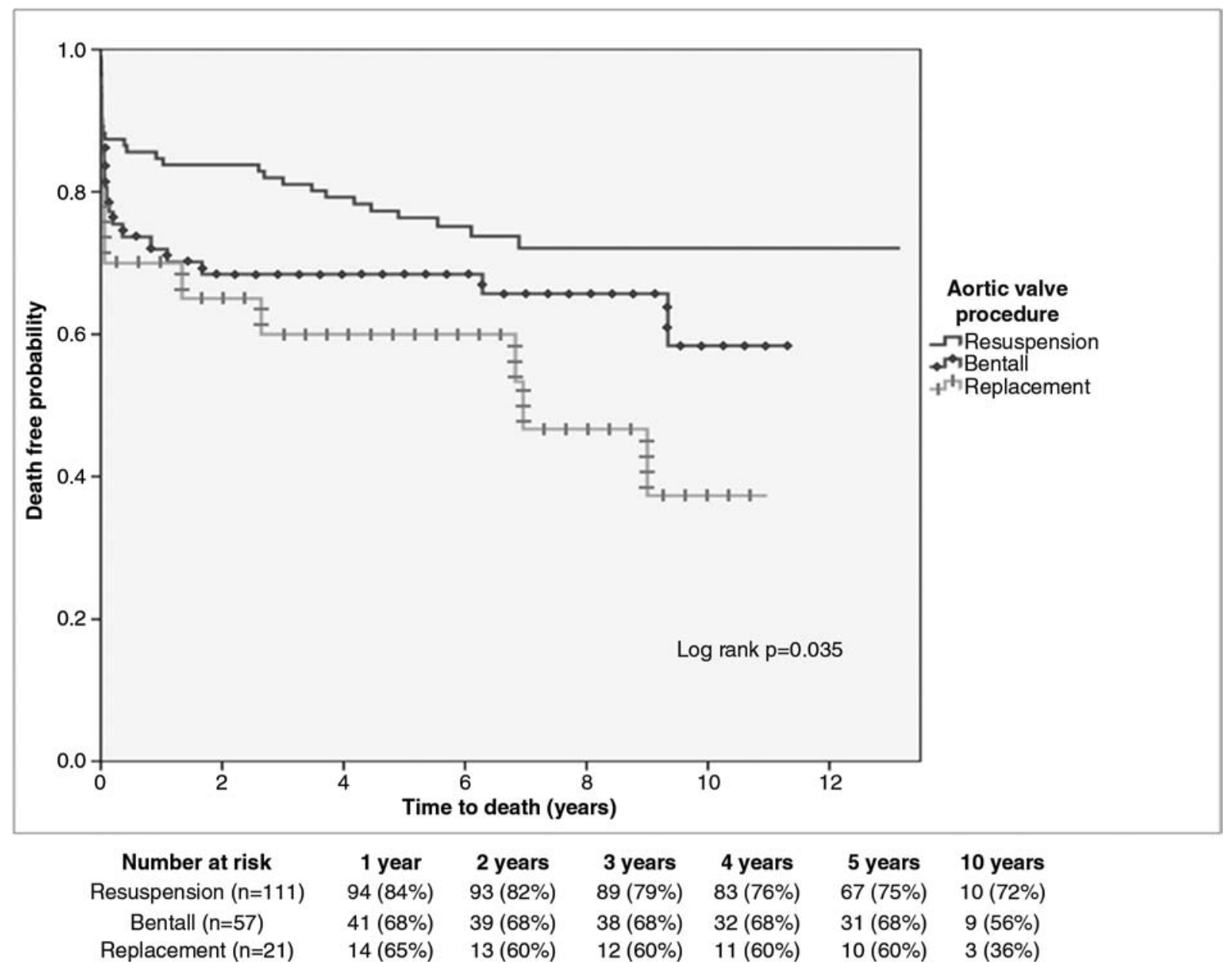

Figure 1. Unadjusted Kaplan-Meier survival estimates comparing types of aortic root reconstruction.

significant; however, the trend toward a higher mortality for patients undergoing AVR might be related to their advanced age and higher number of medical comorbidities. The mortality rates reported in this study are comparable to those recently described in the literature. Klodell et al. [13] reported an operative mortality of $17 \%$ in a cohort of 190 patients who underwent surgery for acute Type A aortic dissection between 1998 and 2010. In another study, Subramanian et al. [14] calculated an operative mortality of $23 \%$ for 208 patients with acute Type A aortic dissections who underwent surgical repair of the aortic root between 1995 and 2010, as well as an operative mortality of $27 \%$ for those who received a similarly modified Bentall procedure. Lai et al. [15] reported an operative mortality of $16 \%$ in 123 patients with Type $A$ aortic dissection with associated aortic regurgitation between 1967 and 1999. Conversely, a low operative mortality of $10 \%$ was reported by Bavaria et al. [1] in a population of 163 patients who underwent surgical treatment for acute Type A aortic dissection, of which $83 \%$ underwent aortic root repair. Other studies have published operative mortality figures between 14 and $26 \%$ in the setting of acute Type A aortic dissection $[4,6,7,16-18]$. The average mortality decreased from $24 \%$ during the first period of the study (years 2000-2005) to $12 \%$ during the second half, indicating a continuous improvement in preoperative, operative, and postoperative care. Similarly, the postoperative rate of cardiac arrest was halved from $12 \%$ in the first study period to $6 \%$ during the second study period. The relatively high postoperative stroke rate may be due to the high rate of patients who presented with hemodynamic instability. 


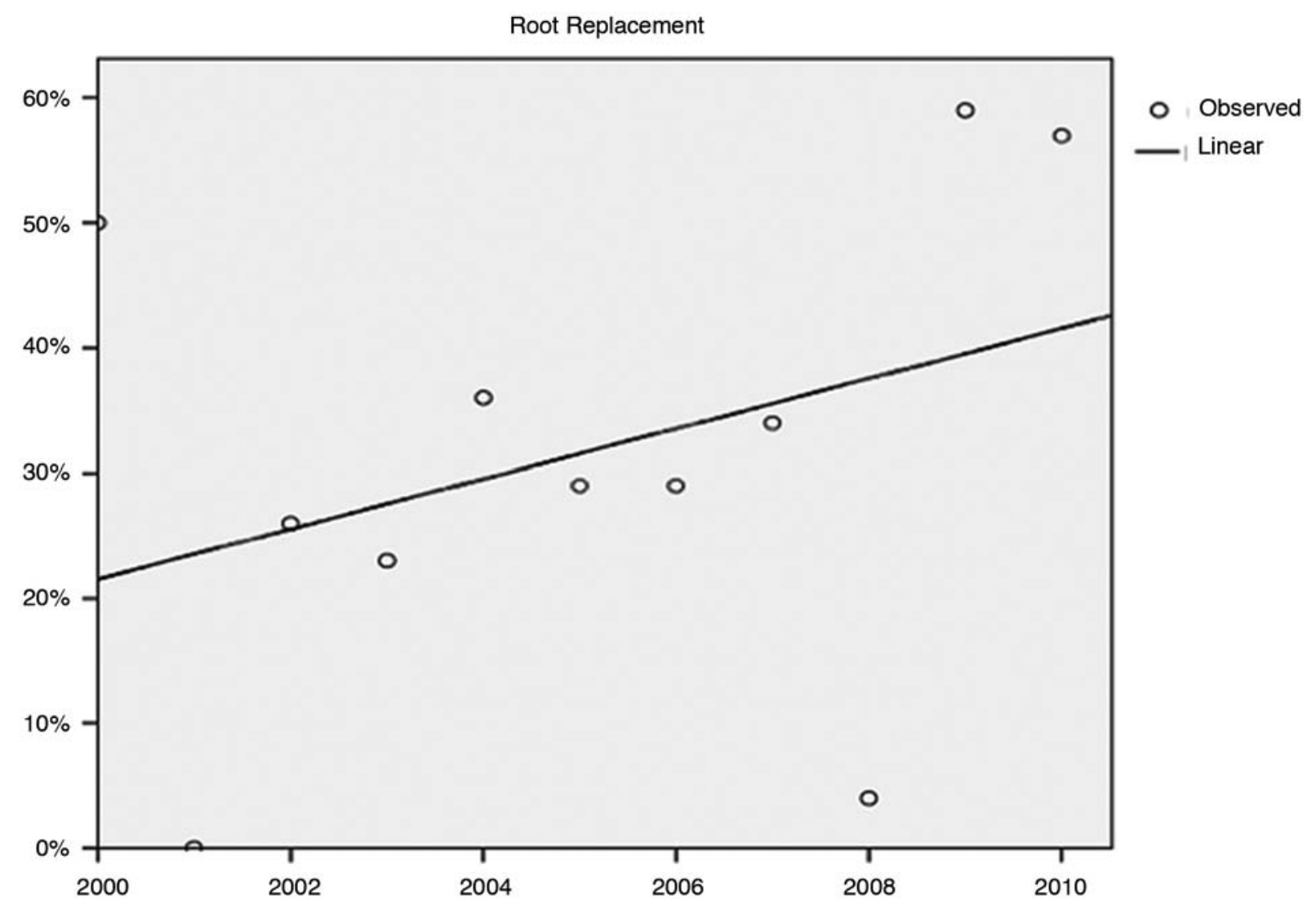

Figure 2. Trends in root replacement procedures (Bentall procedure), over time in patients who underwent acute Type A aortic dissection repair.

\section{Actuarial 10-Year Survival and Trends Over Time}

Survival analyses yielded statistically significant differences between valve procedures, with higher survival rates in patients receiving AV resuspension than those undergoing AVR or Bentall procedures. The survival rates for AV resuspension and root replacement procedures were slightly higher than those reported in other studies, however, survival for AVR was lower. Sabik et al. [19] reported a noticeably decreased survival in patients with root replacement and increased survival of those receiving AVR in a cohort of 208 patients undergoing operations for both acute and chronic ascending aortic dissection between 1978 and 1995. This contradicts with our findings, possibly because the Cleveland Clinic study included both acute and chronic dissections, while our study focused on acute Type A aortic dissections. Consistent with our results, Lai et al. [15] found that there was no significant difference in long-term overall survival rates among these three surgical techniques; however, midterm survival (4-6 years) tended to be lower for those patients receiving AVR, which is again in accordance with our findings. Over time, we noticed an increased rate of root replacements in patients with Type A aortic dissection, which can be partially explained by the accumulated surgical experience that allowed more surgeons to perform root replacement in the face of extensive involvement or destruction of the aortic root instead of attempting a root repair as was often done in the early years of the study. In our series, prolonged cardiopulmonary bypass was found to be an independent predictor of mortality regardless of the aortic valve procedure. Although more time consuming, root replacement is required in patients with destroyed roots and results in better outcomes compared to aortic valve replacement 
that leaves diseased aortic tissue that may result in bleeding or other complications. The higher incidence of cardiac arrest in patients with aortic valve replacement may be related to complications from the proximal diseased root, such as bleeding from the reconstructed aortic root or extension of the dissection into the coronary arteries.

\section{Key Findings}

This study is among a few reports in literature evaluating the outcomes of the three main surgical techniques for proximal root reconstruction. Operative mortality was found to be comparable between the three groups in our study. Improved late survival of patients undergoing valve resuspension compared to AVR, as well as comparable survival to those who received Bentall procedures may encourage repair of the native aortic valve when technically feasible. An increasing trend was observed in the proportion of patients receiving root replacement over time. Comorbidities, presentation (with hemodynamic instability), and a prolonged CPB time tend to be the best predictors of surgical outcomes. Early recognition and careful management of aortic dissections remain a top priority for optimizing patient outcomes. The median age of patients undergoing a root replacement was significantly younger than the other two groups, likely due to more extensive involvement or destruction of the aortic root or earlier onset and more extensive pathology in young patients with connective tissue disorders. A history of Marfan syndrome or other connective tissue disorders was not included as a preoperative variable in this study.

\section{Study Limitations}

The inherent limitations of a retrospective multiinstitution study affected our analysis. The findings are limited by evolution of the operation, accumulation of surgical experience, and support techniques across the years. Aortic valve-sparing root replacement (the David procedure) has recently become more popular in the setting of Type A aortic dissection, especially in young and otherwise healthy patients. However, aortic valve-sparing root replacement was not performed in this patient population due to surgeons' preference in the emergent setting of Type A aortic dissection. Potential bias could have been introduced by the fact that nine surgeons from four different institutions contributed to this database. Topics beyond the scope of our study included further investigation regarding the causes of late mortality, reoperations on the remaining dissected aorta, and the fate of the false lumen. Although data from multiple institutions was included, the small sample size is another limitation that did not allow risk-adjusted multivariate analysis and provide better insight into late survival. Future reports evaluating the late outcomes of acute Type A aortic dissection are warranted.

\section{Conclusions}

In our multi-institutional retrospective review of patients undergoing surgical repair of acute Type $A$ aortic dissection, 10-year survival was significantly decreased in those receiving AVR compared to those receiving root replacement procedures or AV resuspension. The overall operative mortality trended downward throughout the study.

\section{Conflict of Interest}

The authors have no conflict of interest relevant to this publication.

\section{Comment on this Article or Ask a Question}

\section{References}

1. Bavaria JE, Brinster DR, Gorman RC, Woo YJ, Gleason T, Pochettino A. Advances in the treatment of acute Type $A$ dissection: an integrated approach. Ann Thorac Surg. 2002;74:S1848-52; DOI: 10.1016/S00034975(02)04128-0

2. Mehta RH, Suzuki T, Hagan PG, Bossone E, Gilon D, Llovet A, et al. Predicting death in patients with acute Type a aortic dissection. Circulation. 2002;105:200-206. DOI: 10.1161/hc0202.102246

3. Stamou SC, Kouchoukos NT, Hagberg RC, Smith CR, Nussbaum M, Hooker RL, et al. Differences in clinical characteristics, management, and outcomes of intraoperative versus spontaneous acute Type $A$ aortic dissection. Ann Thorac Surg. 2013;95:41-45. DOI: 10.1016/j.athoracsur.2012.08.050

4. Hagan PG, Nienaber CA, Isselbacher EM, Bruckman D, Karavite DJ, Russman PL, et al. The International Registry of Acute Aortic Dissection (IRAD): new insights into an old disease. JAMA. 2000;283:897-903. DOI: 10.1001/jama.283.7.897 
5. Mészáros I, Mórocz J, Szlávi J, Schmidt J, Tornóci L, Nagy L, et al. Epidemiology and clinicopathology of aortic dissection. Chest. 2000;117:1271-1278. DOI: 10.1378/ chest.117.5.1271

6. Pacini D, Di Marco L, Fortuna D, Belotti LM, Gabbieri D, Zussa C, et al. Acute aortic dissection: epidemiology and outcomes. Int J Cardiol. 2013;167:2806-2812. DOI: 10.1016/j.ijcard.2012.07.008

7. Olsson C, Thelin S, Ståhle E, Ekbom A, Granath F. Thoracic aortic aneurysm and dissection: increasing prevalence and improved outcomes reported in a nationwide population-based study of more than 14,000 cases from 1987 to 2002 . Circulation. 2006;114:2611-2618. DOI: 10.1161/CIRCULATIONAHA.106.630400

8. Erbel $R$, Alfonso $F$, Boileau $C$, Dirsch $\mathrm{O}$, Eber B, Haverich A, et al. Diagnosis and management of aortic dissection. Eur Heart J. 2001;22:1642-1681. DOI: 10.1053/ euhj.2001.2782

9. Krüger T, Conzelmann LO, Bonser RS, Borger MA, Czerny M, Wildhirt S, et al. Acute aortic dissection Type A. Br J Surg. 2012;99:13311344. DOI: 10.1002/bjs.8840

10. Feldman M, Shah M, Elefteriades JA. Medical management of acute Type A aortic dissection. Ann Thorac Cardiovasc Surg. 2009;15:286-293. PMID: 19901881

11. Krüger T, Weigang $E$, Hoffmann I, Blettner M, Aebert H; GERAADA Investiga- tors. Cerebral protection during surgery for acute aortic dissection Type A: results of the German Registry for Acute Aortic Dissection Type A (GERAADA). Circulation. 2011;124:434-443. DOI: 10.1161/CIRCULATIONAHA.110.009282

12. Kouchoukos NT, Dougenis D. Surgery of the thoracic aorta. N Engl J Med. 1997;336:1876-1888. DOI: 10.1056/ NEJM199706263362606

13. Klodell CT, Karimi A, Beaver TM, Hess PJ, Martin TD. Outcomes for acute Type A aortic dissection: effects of previous cardiac surgery. Ann Thorac Surg. 2012;93:1206-1212; DOI: 10.1016/j.athoracsur.2011.12.076

14. Subramanian $S$, Leontyev $S$, Borger MA, Trommer C, Misfeld M, Mohr FW. Valve-sparing root reconstruction does not compromise survival in acute Type A aortic dissection. Ann Thorac Surg. 2012;94:1230-1234. DOI: 10.1016/j.athoracsur.2012.04.094

15. Lai DT, Miller DC, Mitchell RS, Oyer PE, Moore KA, Robbins RC, et al. Acute Type A aortic dissection complicated by aortic regurgitation: composite valve graft versus separate valve graft versus conservative valve repair. J Thorac Cardiovasc Surg. 2003;126:1978-1986. DOI: 10.1016/S00225223(03)01279-0

16. Goda M, Imoto K, Suzuki S, Uchida K, Yanagi $H$, Yasuda $S$, et al. Risk analysis for hospital mortality in patients with acute
Type a aortic dissection. Ann Thorac Surg. 2010;90:1246-1250. DOI: 10.1016/j. athoracsur.2010.05.069

17. Kazui T, Washiyama N, Bashar AH, Terada $H$, Suzuki T, Ohkura K, et al. Surgical outcome of acute Type A aortic dissection: analysis of risk factors. Ann Thorac Surg. 2002;74:75-81. DOI: 10.1016/S00034975(02)03603-2

18. Olsson C, Hillebrant CG, Liska J, Lockowandt $\mathrm{U}$, Eriksson $\mathrm{P}$, Franco-Cereceda A. Mortality in acute Type A aortic dissection: validation of the Penn classification. Ann Thorac Surg. 2011;92:1376-1382. DOI: 10.1016/j.athoracsur.2011.05.011

19. Sabik JF, Lytle BW, Blackstone EH, McCarthy PM, Loop FD, Cosgrove DM. Long-term effectiveness of operations for ascending aortic dissections. J Thorac Cardiovasc Surg. 2000;119:946-962. DOI: 10.1016/ S0022-5223(00)70090-0

Cite this article as: Gunn TM, Stamou SC, Kouchoukos NT, Lobdell KW, Khabbaz K, Patzelt LH, Hagberg RC. Techniques of Proximal Root Reconstruction and Outcomes Following Repair of Acute Type A Aortic Dissection. AORTA (Stamford). 2016:4(2):33-41. DOI: http://dx.doi.org/10.12945/j.aorta. 2016.14.039 